\title{
Predictors of Achieving Remission among Patients with Psoriatic Arthritis Initiating a Tumor Necrosis Factor Inhibitor
}

\author{
Alexis Ogdie (1), J. Lynn Palmer, Jeffrey Greenberg, Jeffrey R. Curtis (D), Leslie R. Harrold (D), \\ Daniel H. Solomon, Arthur Kavanaugh, Joel M. Kremer, and Philip J. Mease
}

ABSTRACT. Objective. To examine predictors of remission among patients with psoriatic arthritis (PsA) initiating a tumor necrosis factor (TNF) inhibitor.

Methods. Patients with PsA enrolled in the Corrona Registry between 2005 and 2013 were followed from initiation of a TNF inhibitor (TNFi; etanercept, adalimumab, infliximab, certolizumab, or golimumab) to the visit closest to 12 months. Additional inclusion criteria included 3 tender or 3 swollen joints. Outcomes of interest were Clinical Disease Activity Index (CDAI) $\leq 2.8$ (remission), low disease activity (LDA; CDAI $\leq 10)$, change in the modified Health Assessment Questionnaire $(\mathrm{mHAQ}) \geq 0.35$ and achievement of mHAQ $<0.30$. Predictors were measured on or before TNFi initiation. Covariates significant in univariable logistic regression models and $\leq 5 \%$ missing values were included in a multivariable model and removed individually until all remaining variables were significant $(\mathrm{p}<0.05)$.

Results. Among 1832 TNFi initiations, 774 initiations (624 patients) met inclusion criteria. Median age at initiation was 52 years [interquartile range (IQR) 44-60], 56\% were female, median PsA duration was 4 years (IQR 2-11), and median CDAI at baseline was 20 (IQR 14.5-28). Remission was achieved by $14 \%$ and LDA (or remission) by $37 \%$. Achieving remission was positively associated with college education (OR $1.88,95 \%$ CI 1.11-3.19) but negatively associated with female sex (0.62, $95 \%$ CI $0.40-0.97)$, obese body mass index $(0.51,95 \%$ CI $0.32-0.81)$, hypertension $(0.55,95 \%$ CI $0.32-0.95)$, previous biologic use $(0.41,95 \%$ CI $0.26-0.65)$, and baseline pain $(0.80$ per $10 \mathrm{~mm}$ visual analog scale, 95\% CI 0.73-0.87). Predictors for LDA, mHAQ $<0.30$, and mHAQ change were similar. Conclusion. Few patients with PSA in a US-based registry achieved remission by CDAI criteria. Female sex, obesity, comorbidities, and education influence achievement of remission on a TNFi. (First Release January 15 2019; J Rheumatol 2019;46:475-82; doi:10.3899/jrheum.171034)

Key Indexing Terms: PSORIATIC ARTHRITIS THERAPY RESPONSE

TNF INHIBITORS OUTCOMES EPIDEMIOLOGY

From the University of Pennsylvania, Philadelphia, Pennsylvania: Corrona Research Foundation; New York University Hospital for Joint Diseases, New York, New York; University of Alabama at Birmingham, Birmingham, Alabama; University of Massachusetts, Worcester; Brigham and Women's Hospital, Boston, Massachusetts; University of California San Diego, San Diego, California; Albany Medical College, Albany, New York; Swedish Medical Center; University of Washington, Seattle, Washington, USA.

This study was supported by the Corrona Research Foundation. Dr. Ogdie is supported by K23 AR063764, R01 AR072363, and the Rheumatology Research Foundation. Dr. Solomon's work on this project was supported by Corrona and NIH-K24AR055989. The authors have reported potential conflicts of interest; we have listed only COI with a value $>\$ 10,000$ during the past 12 months. Dr. Ogdie has received grants to the University of Pennsylvania from Pfizer (co-investigator) and Novartis (primary investigator). Dr. Palmer is an employee of Corrona. Dr. Greenberg is an employee and shareholder for Corrona LLC. Dr. Curtis has received grants from Pfizer and Lilly. Dr. Harrold has stock from Corrona LLC and is an employee of University of Massachusetts Medical School and Corrona LLC. Dr. Solomon receives salary support through research grants with his institution from Amgen, Bristol Myers Squibb, Genentech, Abbvie, and Ironwood. Dr. Kavanaugh has conducted clinical trials sponsored by and/or consulted for AbbVie, Eli Lilly, and Pfizer. Dr. Kremer is an employee of Corrona. Dr. Mease has received research grants, consulting honoraria, and/or speaker fees from Abbvie, Amgen, Celgene, Lilly, Novartis, and Pfizer.

\begin{abstract}
A. Ogdie, MD, MSCE, University of Pennsylvania; J.L. Palmer, PhD, Corrona Research Foundation; J. Greenberg, MD, New York University Hospital for Joint Diseases; J.R. Curtis, MD, MS, MPH, University of Alabama at Birmingham; L.R. Harrold, MD, MPH, Corrona Research Foundation; D.H. Solomon, MD, MPH, Brigham and Women's Hospital; A. Kavanaugh, MD, University of California at San Diego; J.M. Kremer, MD, Corrona Research Foundation, and Albany Medical College; P.J. Mease, MD, Swedish Medical Center, and University of Washington. Address correspondence to Dr. A. Ogdie, Division of Rheumatology, Center for Clinical Epidemiology and Biostatistics, Perelman School of Medicine, University of Pennsylvania, Philadelphia, Pennsylvania, USA. E-mail: alexis.ogdie@uphs.upenn.edu

Accepted for publication August 9, 2018.
\end{abstract}

Psoriatic arthritis (PsA) is a chronic inflammatory arthritis associated with psoriasis that can have a devastating effect on a patient's functional ability and quality of life ${ }^{1}$. While the number of therapies for PsA has rapidly expanded, fewer than $60 \%$ of patients achieve a $20 \%$ improvement in clinical trials $^{2}$. Tumor necrosis factor inhibitors (TNFi) are among the most commonly used therapies for PsA in the United States. While many patients respond well to these medica-

Personal non-commercial use only. The Journal of Rheumatology Copyright @ 2019 . All rights reserved. 
tions, some may not respond, and other treatments may lose effectiveness over time ${ }^{2}$. Relatively few studies have addressed predictors of response to $\mathrm{TNFi}^{3,4,5,6,7,8,9}$. Understanding which patients are most likely to respond to a given therapy may help us better select therapies for the individual patient and may likewise tell us more about how to best measure response. Further, identifying which patients are less likely to respond to therapy may assist in determining mechanisms for nonresponse.

The objective of this study was to examine predictors of remission and low disease activity (LDA) defined by the Clinical Disease Activity Index (CDAI) at 1 year among patients with PsA initiating a TNFi. Additionally, we examined predictors of a change in modified Health Assessment Questionnaire (mHAQ) among the same cohort. The mHAQ is a patient-reported assessment of function. According to patients, physical function improvement is one of the most highly rated reasons for pursuing therapy ${ }^{10}$. We used data from Corrona, a national registry with physicianrecorded disease activity and patient-reported outcome measures among a large cohort of patients with PsA in the United States.

\section{MATERIALS AND METHODS}

Study design and setting. A cohort study was conducted within Corrona, a US-based registry ${ }^{11}$. The Corrona registry is a multicenter longitudinal cohort enrolling patients across the US. Data on 27,800 patient visits and mean time of patient followup of 3.8 years were collected between 2003 and 2013 for patients with PsA from both academic $(n=21)$ and private $(n=85)$ clinical sites. In March 2013, during the last year of this analysis, the PsA registry expanded its scope to include detailed assessment of enthesitis, dactylitis, axial, and skin disease, which had not been collected previously; thus, these data were not available for the majority of visits. Clinical information was collected from patients and physicians at 3- to 6-month intervals. Previous studies have published data on the PsA population within Corrona ${ }^{11,12,13,14,15,16}$.

Study population. Patients with rheumatologist-diagnosed PsA were enrolled in the Corrona Registry between 2005 and 2013, and were initiating a new TNFi [etanercept (ETN), adalimumab (ADA), infliximab (IFX), certolizumab, or golimumab (GOL)]. Patients were required to have at least 3 tender or swollen joints for inclusion in this study (not inclusion criteria for the Corrona registry). This requirement somewhat mirrors PsA trials (in which patients are restricted to 3 tender and 3 swollen joints) and increases the likelihood that patients were starting or switching therapies for active inflammatory arthritis rather than psoriasis alone in the setting of quiescent joint disease. We selected a cutoff of 3 tender or swollen joints for 2 reasons: (1) if the joint count was too low, it would be difficult to demonstrate a change or overall improvement using the CDAI; and (2) the CDAI, the primary outcome of interest, includes a 28 -joint count that may not adequately measure oligoarticular arthritis (particularly joint counts $<3$ ) in patients with PsA ${ }^{17}$. Patients need not have been biologic-naive and could enter the cohort more than once if they initiated $>1$ TNFi during their time in Corrona and satisfied the inclusion criteria for each initiation. Patients could not have previously taken the TNFi for which they were entering the cohort (i.e., a new user design was used). Patients meeting the outcome of interest at baseline were excluded from those particular models (e.g., for the outcome $\mathrm{CDAI}<10$, patients with a $\mathrm{CDAI}<10$ at baseline were excluded). All patients provided written informed consent prior to enrollment in Corrona.

Visits. Patients were required to have a baseline visit on the date of the new prescription or within 6 months prior to starting the TNFi and were additionally required to have at least 1 followup visit with a recorded CDAI within at least 24 months of the baseline visit. When more than 1 followup visit occurred in the time frame of interest, we used the visit closest to 12 months. If the drug was discontinued before any followup visit occurred, data from the followup visit were not included; in this case, the patient was considered a nonresponder. In a sensitivity analysis, we limited the cohort to patients with a visit specifically within 5-13 months after therapy initiation.

Outcomes. The primary outcome of interest was CDAI $\leq 2.8$ (remission) at the visit closest to 12 months. CDAI was the best disease activity measure available in this registry during the study period as more specific PsA disease activity measures had not yet been developed. Additionally, CDAI remains among the most commonly assessed outcome measures for inflammatory arthritis within clinical practice in the United States. Currently available composite measures for PsA, such as minimal disease activity, could not be calculated because dactylitis and enthesitis were not assessed until the last year of this analysis. Secondary outcomes of interest included CDAI $<10$ at 1 year (LDA), attainment of a "mild" mHAQ (defined as an mHAQ score $<1.3^{18}$ ), and improvement in mHAQ of $>0.35$ (the minimal clinically important improvement in PsA) ${ }^{19}$. The mHAQ was calculated using total score of mHAQ divided by number of non-missing mHAQ items (must have $>6$ items complete)

Predictors. Covariates of interest included baseline demographics (e.g., age, sex, race, work status, education level, marital status), duration of PsA, disease manifestations [e.g., swollen and tender joint counts, enthesitis and dactylitis when available, inflammatory back pain, sacroiliac joint radiographs, and magnetic resonance imaging changes consistent with axial spondyloarthritis, baseline CDAI, rheumatoid factor or cyclic citrullinated peptide positivity, C-reactive protein (CRP) elevation, erythrocyte sedimentation rate elevation], patient-reported outcomes (e.g., pain, fatigue, function/mHAQ, global assessment), comorbidities [e.g., body mass index, hypertension (HTN), diabetes, cardiovascular disease], smoking and alcohol intake, concurrent therapy [methotrexate (MTX), nonsteroidal antiinflammatory drugs, glucocorticoids], and previous biologic use. Because of the number of predictors examined, not all the results are shown, to make the sizes of data tables manageable.

Statistical analysis. Univariable associations between covariates and achieving remission at 12 months were tested. Covariates with $\mathrm{p}$ value $\leq$ 0.10 and $\leq 5 \%$ missing values were included in a multivariable logistic regression model and removed individually until all remaining variables were significant $(\mathrm{p}<0.05)$. The same modeling procedures were used for LDA as the outcome of interest and mHAQ score, to compare and contrast the consistency of the predictors across the 3 outcomes. Predictors of the final mHAQ score were examined using generalized linear models.

Sensitivity analyses. Sensitivity analyses were performed to test the validity of the results including (1) restricting the cohort to the first TNFi course contributed by an individual patient, (2) forcing factors considered "important" (e.g., age, sex, calendar year, education, and concurrent MTX use into subsequent versions of the models), (3) redefining the dates of inclusion and restricting the patient population (e.g., including only patients who continued taking the drug for at least 5 months, requiring a followup visit 5-13 months after starting therapy), and (4) using complete case analysis instead of nonresponder imputation and last observation carried forward.

Ethics approval. Institutional review board (IRB) approval was obtained from academic sites and a central IRB (New England IRB 120160610). Written consent was obtained from all patients prior to enrollment. Only de-identified patient data were used in this study.

\section{RESULTS}

Among 1832 TNFi initiations for patients with PsA, 774 initiations met inclusion/exclusion criteria among 624 unique patients. The most common reason for exclusion was having 
$<3$ tender and swollen joints at initiation of the TNFi (Figure 1). Therapies initiated included ADA $(n=293)$, IFX $(\mathrm{n}=184)$, ETN $(\mathrm{n}=181)$, GOL $(\mathrm{SQ}, \mathrm{n}=106)$, and certolizumab $(\mathrm{n}=10)$. Median time receiving therapy until discontinuation was 10 months [interquartile range (IQR) 6-13 months, minimum $<1$ and maximum 24 months]. Baseline characteristics and differences by achievement of remission are shown in Table 1. Baseline characteristics and differences by achievement of LDA are shown in Supplementary Table 1 (available with the online version of this article). Median age at therapy initiation was 52 years (IQR 44-60) and 56\% were female. Median baseline CDAI was 20 (IQR 15-28) and no patients had a baseline CDAI $<2.8$ at baseline, median PsA duration was 4 years (IQR 2-11), and 35\% of those with radiographs had erosions at baseline.

\section{1,832 TNFi initiations}

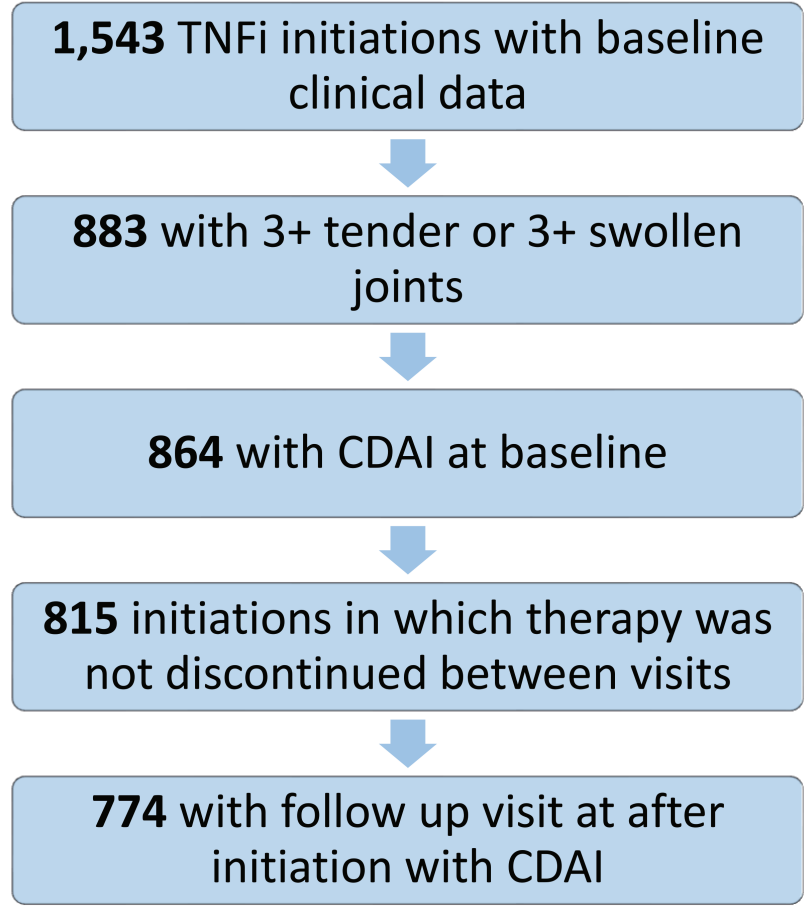

Figure 1. Application of inclusion and exclusion criteria to arrive at patient population of interest. Among PsA visits in the Corrona database, there were 1832 initiations of certolizumab, etanercept, adalimumab, infliximab, or golimumab among patients with PsA. Among these, 1543 initiations had a baseline visit for clinical assessment; this was most frequently on the date of initiation or by defining within 6 months prior to initiating therapy. Of these, 864 also had a recorded CDAI score at baseline and either a tender joint count or swollen joint count of 3 or more. There were 815 who did not discontinue the new drug between Corrona visits. Finally, 774 had at least 1 Corrona followup visit after initiation with a followup CDAI. PsA: psoriatic arthritis; CDAI: Clinical Disease Activity Index; TNFi: tumor necrosis factor inhibitors.
Remission $(\mathrm{CDAI} \leq 2.8)$, the primary outcome, was achieved by $14 \%(\mathrm{n}=109)$. $\mathrm{LDA}(\mathrm{CDAI} \leq 10)$ was achieved by $37 \%$ of patients with a CDAI $>10$ at baseline $(n=706)$. Univariable predictors of achieving remission or LDA were similar (Table 2 and Table 3, respectively). In the multivariable model (Table 2), these patients were less likely to achieve remission: females (OR 0.62, 95\% CI 0.40-0.97), obese patients $(0.51,95 \%$ CI $0.32-0.81)$, patients with HTN $(0.55,95 \%$ CI $0.32-0.95)$, patients having pain at baseline (0.80 per $10 \mathrm{~mm}, 95 \%$ CI $0.73-0.87)$, and patients with any previous biologic use $(0.41,95 \%$ CI $0.26-0.65)$, whereas college education was positively associated with achieving remission $(1.88,95 \%$ CI 1.11-3.19). In these models, education and work status were strongly associated, and because of collinearity, only 1 remained in the final model. Predictors of LDA were similar (Table 3): female sex $(0.56$, 95\% CI 0.40-0.77), baseline CDAI ( 0.89 per 5 units, $95 \%$ CI $0.81-0.97)$, baseline pain score $(0.93$ per $10 \mathrm{~mm}, 95 \% \mathrm{CI}$ $0.87-0.99)$, and any previous biologic use $(0.49,95 \%$ CI 0.35-0.67). In these models, concurrent use of MTX (or other oral agents) at baseline was not associated with remission or LDA. Additional models forcing other covariates are shown in Supplementary Tables 2-3 (available with the online version of this article).

Among patients with mHAQ at both visits $(\mathrm{n}=771)$ and baseline score $>0.35(n=462)$, the mean change in mHAQ was -0.182 (SD 0.41) and the median change was -0.125 (IQR -0.375 to 0 ). Predictors of the final mHAQ score and a clinically important change in mHAQ were also similar (Table 4, and Supplementary Tables 4-5, available with the online version of this article). The baseline value of the mHAQ was the strongest predictor of the followup mHAQ score, and only the baseline mHAQ and age at initiation predicted a change of 0.35 or more in a multivariable model.

\section{DISCUSSION}

Among patients with PsA who were initiating a TNFi, $\leq 25 \%$ achieved remission by 12 months, fewer than half achieved LDA, and one-third of those with a sufficiently elevated score at baseline achieved a clinically important improvement in physical function as measured by the mHAQ. Overall, these factors were negative predictors of poor response: female sex, obesity, HTN and/or cardiovascular disease, smoking, higher baseline disease activity (specifically, CDAI and baseline pain), and any previous biologic use. We also found that higher education level was associated with a better response and increased age was associated with less improvement in physical function. From a population health perspective, knowledge of such risk factors is important for identification of subpopulations of patients who respond differentially to therapy and to further determine the biologic mechanisms for this differential response, ultimately providing a basis for "personalized medicine." Some of these factors are modifiable (e.g., smoking and obesity), some may be biologic

Personal non-commercial use only. The Journal of Rheumatology Copyright (c) 2019. All rights reserved. 
Table 1. Demographics and clinical characteristics overall and by outcome $(\mathrm{N}=774)$.

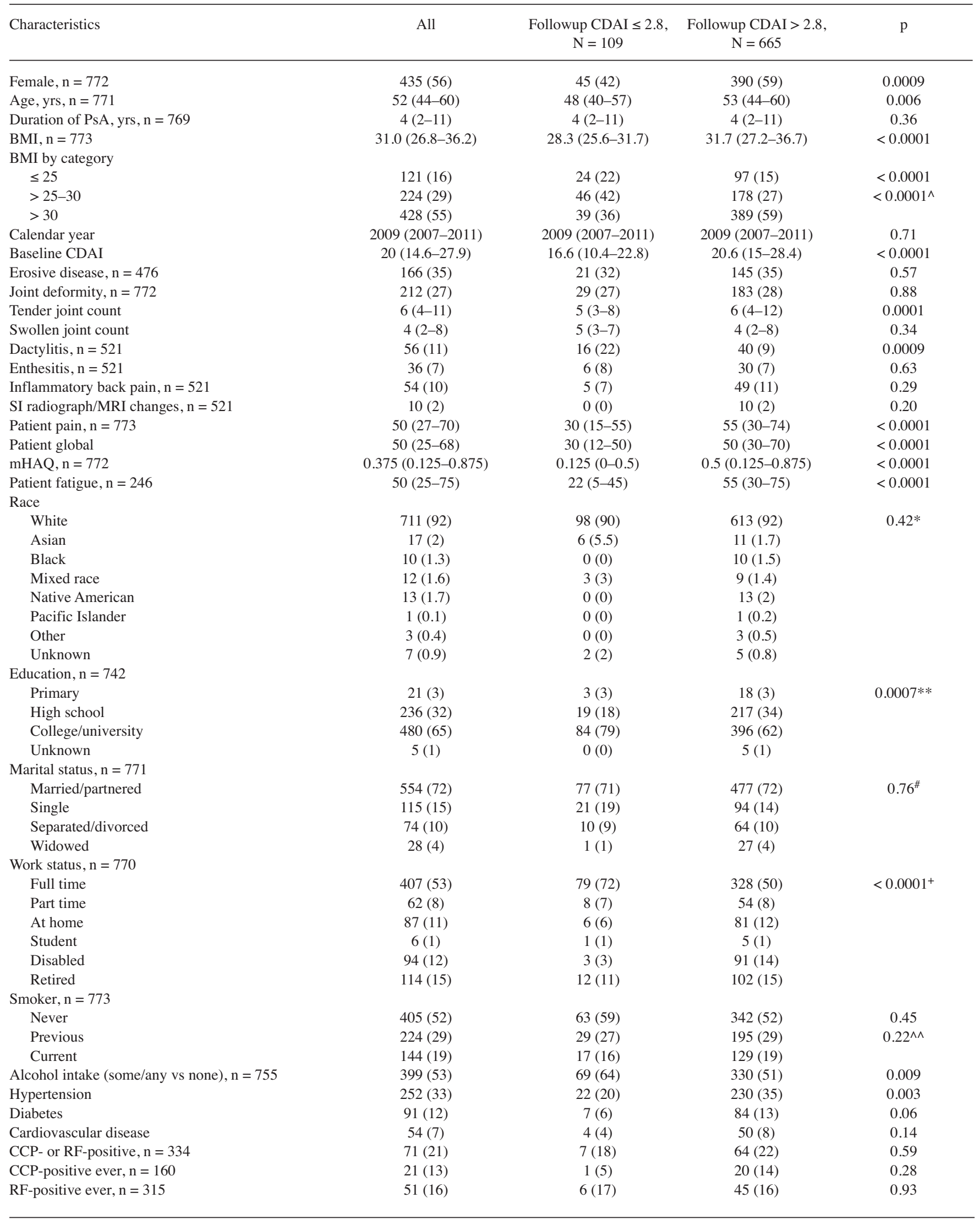


Table 1. Continued.

\begin{tabular}{|c|c|c|c|c|}
\hline Characteristics & All & $\begin{array}{c}\text { Followup CDAI } \leq 2.8 \\
\mathrm{~N}=109\end{array}$ & $\begin{array}{l}\text { Followup CDAI }>2.8 \\
\text { or Early Disc, } \mathrm{N}=665\end{array}$ & $\mathrm{p}$ \\
\hline CRP, $n=249$ & $4(1.7-11)$ & $5(2-25)$ & $4(1.4-10)$ & 0.16 \\
\hline Current prednisone & $109(14)$ & $11(10)$ & $98(15)$ & 0.20 \\
\hline Current NSAID, $\mathrm{n}=766$ & $399(52)$ & $64(59)$ & $335(51)$ & 0.13 \\
\hline Current methotrexate & $418(54)$ & $56(51)$ & $362(54)$ & 0.55 \\
\hline
\end{tabular}

The number of patients with complete data on a given covariate is provided as the " $\mathrm{n}$ " next to each row heading. Values are n (\%) or median (IQR). ^ $\mathrm{P}$ value for BMI category compares $\leq 30$ vs $>30$. * P value for race: white race vs all other races combined. ** P value for education: college vs other. ${ }^{\#} \mathrm{P}$ value for marital status: single/separated/divorced/widowed vs married/partnered. ${ }^{+} \mathrm{P}$ value test for work status: full-time work status vs other categories $\wedge \wedge \mathrm{P}$ value for smoker combines previous and current vs never smoker. IQR: interquartile range; PsA: psoriatic arthritis; CDAI: Clinical Disease Activity Index; BMI: body mass index; SI: sacroiliac; MRI: magnetic resonance imaging; mHAQ: modified Health Assessment Questionnaire; CCP: cyclic citrullinated peptide; RF: rheumatoid factor; CRP: C-reactive protein; ESR: erythrocyte sedimentation rate; NSAID: nonsteroidal antiinflammatory drug.

Table 2. Predictors of achieving remission $(\mathrm{CDAI} \leq 2.8)$.

\begin{tabular}{lcccc}
\hline \multirow{2}{*}{ Predictor } & \multicolumn{2}{c}{ Univariable } & \multicolumn{2}{c}{ Multivariable } \\
& OR & $95 \% \mathrm{CI}$ & OR & $95 \%$ CI \\
\hline Female sex & 0.50 & $0.33-0.76$ & 0.62 & $0.40-0.97$ \\
Age, yrs & 0.98 & $0.96-0.99$ & & \\
BMI (per 1 unit kg/m²) & 0.93 & $0.90-0.96$ & & $0.32-0.81$ \\
BMI > 30 vs $\leq 30$ & 0.39 & $0.26-0.60$ & 0.51 & \\
Baseline CDAI (per 5 units) & 0.76 & $0.67-0.85$ & & $0.73-0.87$ \\
Tender joint count* & 0.92 & $0.88-0.95$ & & \\
Patient pain (per 10 mm) & 0.76 & $0.70-0.83$ & 0.80 & \\
Patient global (per 10 units)* & 0.74 & $0.68-0.81$ & & \\
mHAQ (per 0.125 units) & 0.83 & $0.77-0.89$ & & \\
College education & 2.31 & $1.41-3.80$ & 1.88 & \\
Full-time work & 2.67 & $1.71-4.18$ & & \\
Alcohol intake (yes/no) & 1.75 & $1.14-2.68$ & & \\
Hypertension & 0.48 & $0.29-0.78$ & 0.55 \\
Diabetes & 0.48 & $0.21-1.06$ & & \\
Cardiovascular disease & 0.49 & $0.17-1.39$ & & \\
Smoker (previous/current) vs never & 0.78 & $0.52-1.17$ & & \\
Current methotrexate & 0.88 & $0.59-1.33$ & \multirow{2}{*}{$0.26-0.65$} \\
Any previous biologic use & 0.38 & $0.25-0.58$ & 0.41 & \\
Calendar year & 1.01 & $0.93-1.10$ & &
\end{tabular}

Not all variables are shown in this table if they were not significant at the multivariable level. Other univariable relationships can be found in Table 1.* Tender joint counts and patient global are part of the CDAI and thus were not included in the final model. All patients had a baseline CDAI > $2.8(\mathrm{~N}=774)$. C-statistic $=0.776$. BMI: body mass index; CDAI: Clinical Disease Activity Index; mHAQ: modified Health Assessment Questionnaire.

(e.g., sex) and warrant further scientific investigation, and others may identify a patient "phenotype" that may be generally more challenging to treat (e.g., patients with comorbidities) and in these cases we may focus on understanding adjunct therapies (e.g., treatment of the comorbidity). Moreover, identification of subgroups that respond differentially may also lead us to reexamine our outcome measurement instruments for defining response.

The findings from this US-based study are similar to those from Europe and Canada. Previous studies have identified male sex, younger age, higher CRP, and MTX use as positively associated with achievement of response [generally defined by European League Against Rheumatism or American College of Rheumatology 20 (ACR20) response criteria]. Additionally, female sex, higher baseline global assessment, smoking, obesity, fatty liver disease, and metabolic syndrome have also been reported as negatively associated with response or persistence $e^{3,4,7,8,20-24}$. No available studies have examined CDAI change, a continuous measure, as the outcome of interest. Interestingly, the OR for response in our study are similar to those reported in these studies from DANBIO, a Danish cohort, and ICEBIO, a similar cohort in Iceland. However, despite many similarities with other studies, ours is the first study, to our knowledge, to identify the effect of education and work status, markers of socioeconomic status, on response.

Personal non-commercial use only. The Journal of Rheumatology Copyright $\odot$ 2019. All rights reserved. 
Table 3. Predictors of achieving low disease activity (CDAI $\leq 10)$.

\begin{tabular}{|c|c|c|c|c|}
\hline \multirow[t]{2}{*}{ Predictor } & \multicolumn{2}{|c|}{ Univariable } & \multicolumn{2}{|c|}{ Multivariable } \\
\hline & OR & $95 \% \mathrm{CI}$ & OR & $95 \% \mathrm{CI}$ \\
\hline Female sex & 0.49 & $0.36-0.67$ & 0.56 & $0.40-0.77$ \\
\hline Age, yrs & 0.99 & $0.98-1.004$ & 0.99 & $0.98-1.01$ \\
\hline BMI (per 1 unit kg/m²) & 0.98 & $0.96-0.998$ & & \\
\hline $\mathrm{BMI}>30$ vs $\leq 30$ & 0.69 & $0.51-0.94$ & & \\
\hline Baseline CDAI (per 5 units) & 0.85 & $0.78-0.92$ & 0.89 & $0.81-0.97$ \\
\hline Tender joint count* & 0.94 & $0.92-0.97$ & & \\
\hline Patient pain (per $10 \mathrm{~mm}$ ) & 0.88 & $0.82-0.94$ & 0.93 & $0.87-0.99$ \\
\hline Patient global (per 10 units)* & 0.86 & $0.80-0.92$ & & \\
\hline mHAQ (per 0.125 units) & 0.93 & $0.89-0.97$ & & \\
\hline Full-time work & 1.65 & $1.21-2.25$ & & \\
\hline College education & 1.29 & $0.93-1.80$ & & \\
\hline Smoker (previous/current) vs never & 0.71 & $0.52-0.96$ & & \\
\hline Hypertension & 0.90 & $0.65-1.25$ & & \\
\hline Diabetes & 0.92 & $0.57-1.47$ & & \\
\hline Cardiovascular disease & 0.92 & $0.49-1.71$ & & \\
\hline Current methotrexate & 1.09 & $0.80-1.48$ & & \\
\hline Previous biologic use & 0.44 & $0.32-0.60$ & 0.49 & $0.35-0.67$ \\
\hline Calendar year & 0.95 & $0.89-1.10$ & & \\
\hline
\end{tabular}

Not all variables are shown in this table if they were not significant at the multivariable level. Other univariable relationships can be found in Supplementary Table 1 (available with the online version of this article). * Tender joint counts and patient global are part of the CDAI and thus were not included in the final model. Only patients with baseline CDAI $>10$ were included in this model $(n=706)$. C-statistic $=0.668$. BMI: body mass index; CDAI: Clinical Disease Activity Index; mHAQ: modified Health Assessment Questionnaire.

Table 4. Predictors of achieving modified Health Assessment Questionnaire (mHAQ) $<0.3$.

\begin{tabular}{lcccc}
\hline Predictor & \multicolumn{2}{c}{ Univariable } & \multicolumn{2}{c}{ Multivariable } \\
& OR & $95 \%$ CI & OR & $95 \%$ CI \\
\hline Female sex & 0.66 & $0.43-1.003$ & & \\
Age at initiation, yrs & 0.97 & $0.96-0.99$ & 0.98 & $0.96-0.99$ \\
BMI > 30 (vs $\leq 30$ ) & 0.51 & $0.33-0.77$ & 0.60 & $0.38-0.94$ \\
Duration of PsA, yrs & 0.98 & $0.95-1.003$ & & \\
Baseline mHAQ (per 0.125)* & 0.80 & $0.73-0.88$ & 0.78 & $0.71-0.86$ \\
Hypertension & 0.46 & $0.29-0.74$ & 0.58 & $0.35-0.98$ \\
Cardiovascular disease & 0.33 & $0.11-0.94$ & & \\
Diabetes & 0.69 & $0.36-1.32$ & & \\
Full-time work & 2.22 & $1.46-3.38$ & & \\
Smoker (previous/current) vs never & 0.74 & $0.49-1.12$ & & \\
Alcohol (some/any vs none) & 1.69 & $1.11-2.58$ & & \\
Current methotrexate & 1.23 & $0.81-1.86$ & & \\
Previous biologic use & 0.53 & $0.35-0.81$ & 0.56 & \\
College education & 1.06 & $0.69-1.63$ & & \\
Married/partnered & 0.75 & $0.48-1.15$ & & \\
Prednisone & 0.59 & $0.32-1.09$ & & \\
Patient global & 0.989 & $0.979-0.998$ & & \\
Patient pain & 0.990 & $0.981-1.000$ & & \\
Baseline CDAI (per 5 units) & 0.986 & $0.90-1.08$ & & \\
Tender joint count & 0.965 & $0.936-0.995$ & & \\
Swollen joint count & 1.048 & $1.014-1.084$ & & \\
Calendar year & 0.96 & $0.88-1.04$ & & \\
& & & & \\
\end{tabular}

*mHAQ ranges from 0 to 3 and the minimal clinically important improvement for PsA is about 0.35 ; a score $<0.3$ is considered "normal." Only patients with mHAQ $>0.3$ at baseline were included in this model $(\mathrm{n}=462)$. Among these, 122 achieved a normal mHAQ at followup (26.4\%). Model C-statistic $=0.728$. BMI: body mass index; PsA: psoriatic arthritis; CDAI: Clinical Disease Activity Index. 
While there has been variability in the predictors of response by study, the most consistently identified are sex and baseline disease activity. Increasing evidence points to sex as an important biologic variable ${ }^{25}$. It remains unclear whether the difference in response by sex is related to genetic, epigenetic, immunologic, fat distribution, or hormonal differences that affect the disease or the processing of the drugs. Alternatively, psychophysiological factors that differ by sex, such as central sensitization, may influence the assessment of joint tenderness and/or patient-reported measures, thus blunting the degree of response ${ }^{26}$. However, another study from Italy reported a lower response among women for achieving Psoriasis Area and Severity Index 75 (PASI75; men vs women, OR $2.59,95 \% \mathrm{CI} 1.36-4.94)^{27}$. The fact that there were measurable differences in PASI75 responses, a physician-assessed measure without patient input, suggests that psychophysiological factors do not completely explain the differences.

Additionally, we examined mHAQ response. An alternative version of the mHAQ, the HAQ Disability Index is one of the measures included in the ACR20 and in all clinical trials in PsA. Our data suggest that change in physical function and disability as measured by mHAQ is mostly driven by the baseline score with some influence from age. Thus, the mHAQ may be a better measure of damage or disability than disease activity and may not be an ideal measure of "response" given the floor effect ${ }^{28,29,30}$.

The strengths of our study include use of a large cohort of patients with PsA representative of patients seen in US clinical practice (including both community and academic sites), the examination of social factors such as education/work status and comorbidities, and the use of CDAI as the primary outcome rather than a composite binary outcome, such as the ACR20. Limitations include lack of PsA-specific disease measures (e.g., enthesitis, dactylitis, axial, and skin disease) during the majority of time of this analysis. These features are recorded in the Corrona Psoriatic Arthritis/Spondyloarthritis Registry relaunched in 2013, but the number of patients was insufficient for study at the time of these analyses. Additionally, we lacked information on some comorbidities (e.g., uveitis), social factors (e.g., participation, socioeconomic status beyond work and education), lifestyle factors (e.g., regularity of exercise), and adherence to therapy, which may all contribute to whether patients respond to therapy.

Next, defining "response" to therapy in PsA is challenging; there is not a gold standard or even an agreed-upon definition of response ${ }^{31}$. Persistence with therapy is one measure for response but may be confounded by other reasons for maintaining or stopping therapy (e.g., insurance coverage, medication side effects, the number of options for subsequent therapies). Finally, patient-defined response and physician-defined response may differ ${ }^{32}$. We chose to use CDAI, a composite measure designed for rheumatoid arthritis and not validated in PsA, because it was the best available disease activity measure assessed in the Corrona registry at that time. CDAI measures peripheral arthritis activity and patient and provider global assessments but does not specifically include enthesitis, dactylitis, or skin or axial disease (though these are often collected by the patient global $)^{33,34,35}$. Thus, a patient could potentially be in CDAI "remission" but have active psoriatic disease. Additionally, use of the 28-joint count in the CDAI may miss important joints (e.g., distal interphalangeal joints, hips, feet) in PsA and required that we included people with a sufficiently high joint count (we chose $\geq 3$ ) to have the opportunity to observe change (in much the same way that randomized controlled trials use this same cutoff ${ }^{17}$. Notably, half of patients starting or switching to a new therapy in this cohort would have been ineligible for a typical PsA randomized controlled trial based on joint counts alone. In restricting our cohort in this way, there was a risk for selection bias that has implications for generalizability of the results to the full population of patients with PsA, in particular, the proportion of patients achieving remission (because many who are in LDA or remission were excluded by the joint count requirement). These results are most relevant for those with at least 3 tender or swollen joints. While CDAI is not a perfect instrument for PsA, this measure does appear to work relatively well in PsA ${ }^{36}$.

We confirmed that sex, obesity, and baseline disease activity are important predictors of achieving remission and/or LDA among patients with PsA initiating TNFi. In addition, we identified other baseline characteristics associated with poor outcomes including HTN (likely representative of comorbidities in general), and poor education and lack of full-time work (markers of socioeconomic status). These findings suggest that, among patients with the highest disease activity, we still need additional treatment strategies to get patients to a clinically meaningful "low disease activity" state. Further studies are needed to better understand sex differences in response to therapy among patients with PsA.

\section{ONLINE SUPPLEMENT}

Supplementary material accompanies the online version of this article.

\section{REFERENCES}

1. Ogdie A, Weiss P. The epidemiology of psoriatic arthritis. Rheum Dis Clin North Am 2015;41:545-68.

2. Mease PJ. Biologic therapy for psoriatic arthritis. Rheum Dis Clin of North Am 2015;41:723-38.

3. Glintborg B, Ostergaard M, Dreyer L, Krogh NS, Tarp U, Hansen MS, et al. Treatment response, drug survival, and predictors thereof in 764 patients with psoriatic arthritis treated with anti-tumor necrosis factor $\alpha$ therapy: results from the nationwide Danish DANBIO registry. Arthritis Rheum 2011;63:382-90.

4. Glintborg B, Ostergaard M, Krogh NS, Andersen MD, Tarp U, Loft AG, et al. Clinical response, drug survival, and predictors thereof among 548 patients with psoriatic arthritis who switched tumor necrosis factor $\alpha$ inhibitor therapy: results from the Danish Nationwide DANBIO Registry. Arthritis Rheum 2013;65:1213-23.

Personal non-commercial use only. The Journal of Rheumatology Copyright (c) 2019. All rights reserved. 
5. Eder L, Chandran V, Schentag CT, Shen H, Cook RJ, Gladman DD. Time and predictors of response to tumour necrosis factor-alpha blockers in psoriatic arthritis: an analysis of a longitudinal observational cohort. Rheumatology 2010;49:1361-6.

6. Carvalho PD, Duarte C, Vieira-Sousa E, Cunha-Miranda L, Avila-Ribeiro P, Santos H, et al. Predictors of response to TNF blockers in patients with polyarticular psoriatic arthritis. Acta Rheumatol Port 2017;42:55-65.

7. Hojgaard P, Glintborg B, Hetland ML, Hansen TH, Lage-Hansen $\mathrm{PR}$, Petersen MH, et al. Association between tobacco smoking and response to tumour necrosis factor $\alpha$ inhibitor treatment in psoriatic arthritis: results from the DANBIO registry. Ann Rheum Dis 2015;74:2130-6.

8. Hojgaard P, Glintborg B, Kristensen LE, Gudbjornsson B, Love TJ, Dreyer $\mathrm{L}$. The influence of obesity on response to tumour necrosis factor- $\alpha$ inhibitors in psoriatic arthritis: results from the DANBIO and ICEBIO registries. Rheumatology 2016;55:2191-9.

9. Iannone F, Lopriore S, Bucci R, Scioscia C, Anelli MG, Notarnicola $\mathrm{A}$, et al. Two-year survival rates of anti-TNF- $\alpha$ therapy in psoriatic arthritis (PsA) patients with either polyarticular or oligoarticular PsA. Scand J Rheumatol 2015;44:192-9.

10. Orbai AM, de Wit M, Mease P, Shea JA, Gossec L, Leung YY, et al. International patient and physician consensus on a psoriatic arthritis core outcome set for clinical trials. Ann Rheum Dis 2017;76:673-80.

11. Kremer JM. The Corrona US registry of rheumatic and autoimmune diseases. Clin Exp Rheumatol 2016;5 Suppl 101:S96-9.

12. Greenberg JD, Palmer JB, Li Y, Herrera V, Tsang Y, Liao M. Healthcare resource use and direct costs in patients with ankylosing spondylitis and psoriatic arthritis in a large US cohort. J Rheumatol 2016;43:88-96

13. Gross RL, Schwartzman-Morris JS, Krathen M, Reed G, Chang H, Saunders KC, et al. A comparison of the malignancy incidence among patients with psoriatic arthritis and patients with rheumatoid arthritis in a large US cohort. Arthritis Rheum 2014;66:1472-81.

14. Labitigan M, Bahce-Altuntas A, Kremer JM, Reed G, Greenberg JD, Jordan N, et al. Higher rates and clustering of abnormal lipids, obesity, and diabetes mellitus in psoriatic arthritis compared with rheumatoid arthritis. Arthritis Care Res 2014;66:600-7.

15. Mease PJ, Collier DH, Saunders KC, Li G, Kremer JM, Greenberg JD. Comparative effectiveness of biologic monotherapy versus combination therapy for patients with psoriatic arthritis: results from the Corrona registry. RMD Open 2015;1:e000181.

16. Huynh DH, Boyd TA, Etzel CJ, Cox V, Kremer JM, Mease P, et al. Persistence of low disease activity after tumour necrosis factor inhibitor (TNFi) discontinuation in patients with psoriatic arthritis. RMD Open 2017;3:e000395.

17. Coates LC, FitzGerald O, Gladman DD, McHugh N, Mease P, Strand V, et al. Reduced joint counts misclassify patients with oligoarticular psoriatic arthritis and miss significant numbers of patients with active disease. Arthritis Rheum 2013;65:1504-9.

18. Maska L, Anderson J, Michaud K. Measures of functional status and quality of life in rheumatoid arthritis: Health Assessment Questionnaire Disability Index (HAQ), Modified Health Assessment Questionnaire (MHAQ), Multidimensional Health Assessment Questionnaire (MDHAQ), Health Assessment Questionnaire II (HAQ-II), Improved Health Assessment Questionnaire (Improved HAQ), and Rheumatoid Arthritis Quality of Life (RAQoL). Arthritis Care Res 2011;63 Suppl 11:S4-13.

19. Mease PJ, Woolley JM, Bitman B, Wang BC, Globe DR, Singh A. Minimally important difference of Health Assessment Questionnaire in psoriatic arthritis: relating thresholds of improvement in functional ability to patient-rated importance and satisfaction. J Rheumatol 2011;38:2461-5.

20. Eder L, Thavaneswaran A, Chandran V, Cook RJ, Gladman DD. Obesity is associated with a lower probability of achieving sustained minimal disease activity state among patients with psoriatic arthritis. Ann Rheum Dis 2015;74:813-7.

21. Costa L, Caso F, Ramonda R, Del Puente A, Cantarini L, Darda MA, et al. Metabolic syndrome and its relationship with the achievement of minimal disease activity state in psoriatic arthritis patients: an observational study. Immunologic Res 2015;61:147-53.

22. Stober C, Ye W, Guruparan T, Htut E, Clunie G, Jadon D. Prevalence and predictors of tumour necrosis factor inhibitor persistence in psoriatic arthritis. Rheumatology 2018;57:158-63.

23. di Minno MN, Peluso R, Iervolino S, Lupoli R, Russolillo A, Scarpa $\mathrm{R}$, et al. Obesity and the prediction of minimal disease activity: a prospective study in psoriatic arthritis. Arthritis Care Res 2013;65:141-7.

24. Di Minno MN, Peluso R, Iervolino S, Lupoli R, Russolillo A, Tarantino G, et al. Hepatic steatosis, carotid plaques and achieving MDA in psoriatic arthritis patients starting TNF- $\alpha$ blockers treatment: a prospective study. Arthritis Res Ther 2012;14:R211.

25. Generali E, Scire CA, Cantarini L, Selmi C. Sex Differences in the treatment of psoriatic arthritis: a systematic literature review. Isr Med Assoc J 2016;18:203-8.

26. Mease PJ. Fibromyalgia, a missed comorbidity in spondyloarthritis: prevalence and impact on assessment and treatment. Curr Opinion Rheumatol 2017;29:304-10

27. De Simone C, Caldarola G, Maiorino A, Tassone F, Campana I, Sollena P, et al. Clinical predictors of nonresponse to anti-TNF- $\alpha$ agents in psoriatic patients: A retrospective study. Dermatol Ther 2016;29:372-6.

28. Husted JA, Tom BD, Farewell VT, Schentag CT, Gladman DD. A longitudinal study of the effect of disease activity and clinical damage on physical function over the course of psoriatic arthritis: does the effect change over time? Arthritis Rheum 2007;56:840-9.

29. Leung YY, Tam LS, Kun EW, Ho KW, Li EK. Comparison of 4 functional indexes in psoriatic arthritis with axial or peripheral disease subgroups using Rasch analyses. J Rheumatol 2008;35:1613-21.

30. Molenaar ET, Voskuyl AE, Dijkmans BA. Functional disability in relation to radiological damage and disease activity in patients with rheumatoid arthritis in remission. J Rheumatol 2002;29:267-70.

31. Coates LC, FitzGerald O, Merola JF, Smolen J, van Mens LJJ, Bertheussen H, et al. Group for Research and Assessment of Psoriasis and Psoriatic Arthritis/Outcome Measures in Rheumatology consensus-based recommendations and research agenda for use of composite measures and treatment targets in psoriatic arthritis. Arthritis Rheumatol 2018;70:345-55.

32. Lindstrom Egholm C, Krogh NS, Pincus T, Dreyer L, Ellingsen T, Glintborg B, et al. Discordance of global assessments by patient and physician is higher in female than in male patients regardless of the physician's sex: data on patients with rheumatoid arthritis, axial spondyloarthritis, and psoriatic arthritis from the DANBIO registry. J Rheumatol 2015;42:1781-5.

33. Eder L, Thavaneswaran A, Chandran V, Cook R, Gladman DD. Factors explaining the discrepancy between physician and patient global assessment of joint and skin disease activity in psoriatic arthritis patients. Arthritis Care Res 2015;67:264-72.

34. Smolen JS, Schoels M, Aletaha D. Disease activity and response assessment in psoriatic arthritis using the Disease Activity index for PSoriatic Arthritis (DAPSA). A brief review. Clin Exp Rheumatol 2015;5 Suppl 93:S48-50.

35. Talli S, Etcheto A, Fautrel B, Balanescu A, Braun J, Canete JD, et al. Patient global assessment in psoriatic arthritis - what does it mean? An analysis of 223 patients from the Psoriatic Arthritis Impact of Disease (PsAID) study. Joint Bone Spine 2016;83:335-40.

36. Acosta Felquer ML, Ferreyra Garrott L, Marin J, Catay E, Scolnik $\mathrm{M}$, Scaglioni V, et al. Remission criteria and activity indices in psoriatic arthritis. Clin Rheumatol 2014;33:1323-30. 